\title{
Interleukin-8 and nuclear factor kappa $B$ are increased and positively correlated in myelodysplastic syndrome
}

\author{
Anacélia Gomes de Matos, ${ }^{1,2,5}$ - Howard Lopes Ribeiro Junior ${ }^{1,2,5}$ - Daniela de Paula Borges ${ }^{1,2,5}$. \\ Bruno Memória Okubo ${ }^{1,2} \cdot$ Juliana Cordeiro de Sousa ${ }^{1,2} \cdot$ Maritza Cavalcante Barbosa $^{4}$. \\ Marilena Facundo de Castro ${ }^{4}$ Romélia Pinheiro Gonçalves ${ }^{4} \cdot$ Ronald Feitosa Pinheiro $^{1,2,3,5}$. \\ Silvia Maria Meira Magalhães ${ }^{1,2,3,5}$
}

Received: 14 July 2017/ Accepted: 9 August 2017

(C) Springer Science+Business Media, LLC 2017

\begin{abstract}
The pathogenesis of myelodysplastic syndromes (MDS) is complex and depends on the interaction between aberrant hematopoietic cells and their microenvironment, probably including aberrations in cytokines and their signaling pathways. To evaluate interleukin-8 (IL-8) plasma levels and nuclear factor kappa B (NF-kB) in patients with MDS and to test possible correlation between IL-8 and NF$\mathrm{Kb}$, a total of 45 individuals were analyzed: 25 consecutive adult de novo MDS patients and 20 sex and age-matched healthy elderly volunteers. IL-8 analysis was performed by ELISA and activity of NF-kB by chemiluminescent assay. MDS patients showed higher level of IL- 8 when compared to controls $(p=0.006)$. Patients aged 75 and above showed even higher levels $(p=0.035)$. NF-kB activity was significantly elevated in MDS patients when compared to controls $(p<0.0001)$ and higher in patients older than 75 years $(p=0.047)$. NF-kB activity was associated with higher serum ferritin $(p=0.042)$ and higher percentage of blasts $(p=0.028)$. A significant positive correlation
\end{abstract}

Ronald Feitosa Pinheiro

ronaldfpinheiro@uol.com.br; ronaldpinheiro@pq.cnpq.br

1 Cancer Cytogenomic Laboratory, Federal University of Ceará, Fortaleza, Brazil

2 Post-graduate Program in Medical Science, Federal University of Ceará, Fortaleza, Brazil

3 Department of Clinical Medicine, Federal University of Ceará, Fortaleza, Brazil

4 Department of Clinical and Toxicological Analysis, Federal University of Ceará, Fortaleza, Brazil

5 Center for Research and Drug Development (NPDM), Federal University of Ceará, R. Coronel Nunes de Melo, $1000-2^{\circ}$ andar, Rodolfo Teófilo, Fortaleza, CE CEP 60430-275, Brazil between IL-8 and NF-kB was demonstrated $(r=0.480$; $p=0.015)$. Many pathways involved in pathophysiology of MDS have been recently described, suggesting that an inflammatory process may act as a pathogenic driver. In this study, significantly elevated levels of IL-8 and NF-kB were demonstrated in MDS patients, with positive association of NF-kB with some markers of poor prognosis. A positive correlation between IL- 8 and NF-kB suggests they cooperate as part of a complex networking of immune and inflammatory factors involved in MDS.

Keywords Interleukin-8 (IL-8) · Nuclear factor kappa B (NF-kB) · Proinflammatory cytokine · Myelodysplastic syndrome

\section{Introduction}

Myelodysplastic syndrome (MDS) is a heterogeneous group of hematopoietic stem cell disorders clinically characterized by peripheral cytopenias due to ineffective hematopoiesis and by high risk of progression to acute myeloid leukemia (AML) [1]. It is considered a disease of older people as median age at diagnosis range from 70 to 75 years. In Brazil, there is a slight predominance of female with mean age of 65 years at diagnosis and high prevalence of lower-risk disease [2, 3]. Similar characteristics were recently reported in a Latin American series of 1080 patients [4].

The pathogenesis of MDS is complex and multifactorial and depends on the interaction between aberrant hematopoietic cells and their microenvironment. It is well established that chronic inflammation underpins the development of a number of human cancers. In MDS, many unraveled specific pathways involved in its 
complex pathophysiology have been recently described, including abnormal activation of innate immune signals, elevated proinflammatory cytokines levels and aberrations in their signaling pathways, suggesting that an inflammatory process may act as a pathogenic driver [5-8].

Interleukin-8 (IL-8) is a member of the CXC chemokine superfamily, produced by blood cells and many types of tissues. It activates multiple intracellular signaling pathways, can cause a wide range of proinflammatory chemical reactions and has been recently proposed as a useful biomarker for various clinical conditions [9]. Increased expression of IL-8 and/or its receptors has been reported in cancer cells, endothelial cells, infiltrating neutrophils and tumor-associated macrophages, suggesting that IL-8 may function as a significant regulatory factor within the tumor microenvironment promoting survival, proliferation and invasion of cancer cells, particularly in solid tumors [10]. Overexpression of IL-8 receptor CXCR2 was identified in purified stem cells from AML and MDS and was shown to be associated with worse prognosis $[11,12]$. Blocking the IL-8-CXCR2, therefore, was shown to be of therapeutic potential in a variety of cancers $[11,13]$.

The activation of multiple pathways by IL- 8 leads to increased expression of various transcription factors including nuclear factor kappa B (NF-kB), which promotes survival and tumor growth [14]. However, little is known in hematologic malignancies, particularly in MDS [5].

The NF-kB is a transcription factor that acts as a key component for the expression of a wide variety of cellular genes. It has opposite functions as it is part of cells' auto defense mechanism, but its inappropriate activation can mediate inflammation and tumorigenesis with important role in pathogenesis of several types of tumors and hematologic malignancies [15].

NF-kB is present in cytoplasm of all cells associated with inhibitory kinases $(\mathrm{IkB})$ in an inactive state. After degradation of its inhibitory protein, NF-kB is able to enter the nucleus and regulate transcription of over 150 genes involved in the regulation of fundamental cellular processes such as apoptosis, proliferation, differentiation and tumor migration [16-18].

NF-kB is a molecule of great interest in the study of MDS. Its activity is elevated in bone marrow progenitors and has been correlated with progression of the disease, with higher-risk subgroups presenting the highest activity levels. The aim of this study was to evaluate the IL-8 expression and NF-kB activation in primary MDS, to analyze its association with different clinicopathological variables and to test the possible correlation between these two factors.

\section{Materials and methods}

Consecutive de novo MDS patients diagnosed in a University Hospital were included and classified according to the following variables: gender, age (younger than 75 years and older than 75 years), number of cytopenias according to IPSS-R [19], bone marrow cellularity (i.e., hypocellular, normocellular and hypercellular), karyotype (normal and abnormal), WHO classification (refractory anemia (RA), RA with ring sideroblasts (RARS), refractory cytopenia with multilineage dysplasia (RCMD) and RA with excess blasts (RAEB) [20], IPSS-R score (very low + low risk and intermediate + high + very high risk), serum ferritin $(<500 \mathrm{ng} / \mathrm{mL}$ or $\geq 500 \mathrm{ng} / \mathrm{mL})$, iron overload $(<1000 \mathrm{ng} / \mathrm{mL}$ or $\geq 1000 \mathrm{ng} / \mathrm{mL})$, hemoglobin $(\leq 8,>8$ to $\leq 10,>10 \mathrm{~g} / \mathrm{dL})$, neutrophils count $(<800$ or $\left.\geq 800 / \mathrm{mm}^{3}\right)$, transfusion dependence, platelets count $\left(\leq 50,000 ;>50,000\right.$ to $\left.\leq 100,000 ;>100,000 / \mathrm{mm}^{3}\right)$, erythropoietin levels $(\leq 500,>500 \mathrm{mUL} / \mathrm{mL})$ and percentage of blasts $(<5, \geq 5 \%)$.

Peripheral blood DNA samples were obtained from sex and age-matched healthy elderly volunteers as controls. The study was approved by Committee of Ethics in Research with Human Beings of Walter Cantídio University Hospital/Federal University of Ceara (\#1.359.984) and conducted according to the Declaration of Helsinki. A written informed consent was obtained from all patients and healthy volunteers.

Peripheral blood mononuclear cells (PBMC's) were isolated by Ficoll-Paque ${ }^{\circledR}$ (Density 1.077), according to the manufacturer's instructions (GE Healthcare, Piscataway, NJ, USA). Briefly, to prepare nuclear extract, the PBMC's were washed with ice-cold phosphate-buffered saline (PBS) and lysed using complete lysis buffer. A phosphatase inhibitor was added to circumvent NF-kB protein degradation. The cell suspension was incubated on ice for $15 \mathrm{~min}$ to complete the lysis of cell membrane. After centrifugation, the nuclear pellet was resuspended in an ice-cold extraction buffer. The nuclear lysate containing the nuclear proteins was stored at $80{ }^{\circ} \mathrm{C}$ until further use. The protein concentration was determined using a Bradford-based assay yielding sample concentrations of approximately $1 \mu \mathrm{g} / \mathrm{mL}$ [21].

DNA binding activity of NF-kB p65 was measured using TransAM NF-kB p65 kits ${ }^{\circledR}$ (Active Motif, Carlsbad, California, USA), according to the manufacturer's instructions. Briefly, $20 \mu \mathrm{L}$ of sample per well was incubated for $1 \mathrm{~h}$ at room temperature with mild agitation. After washing 3 times, $50 \mu \mathrm{L}$ of diluted NF-kB antibody was added to each well. The plate was incubated for $1 \mathrm{~h}$ at room temperature and then washed for 3 times. Fifty $\mu \mathrm{L}$ of diluted NF-kB antibody was added to each well followed 
Table 1 Characteristics and classification of MDS patients

\begin{tabular}{|c|c|c|c|c|c|c|}
\hline Cases & Cytogenetic & Gender & $\begin{array}{l}\text { Age } \\
\text { (years) }\end{array}$ & $\mathrm{BMC}$ & IPSS-R & WHO \\
\hline 1 & $\begin{array}{l}47, \mathrm{XX}, \operatorname{del}(5)(\mathrm{q} 31 \mathrm{q} 33),+8[3] / 48, \mathrm{XX},+8,+9[4] / \\
48, \mathrm{XX}, \operatorname{del}(5)(\mathrm{q} 31 \mathrm{q} 33),+8,+9[2] / 46, \mathrm{XX}[3]\end{array}$ & Female & 85 & Hypercellular & Intermediate & $\mathrm{RCDM}$ \\
\hline 2 & 46, XY[20] & Male & 88 & NA & Very low & RARS \\
\hline 3 & 46, XY[20] & Male & 79 & NA & High & RAEB-I \\
\hline 4 & $46 \mathrm{XY}, \operatorname{del}(20)(\mathrm{q} 13.1)[8] / 46, \mathrm{XY}[9]$ & Male & 99 & NA & Low & RARS \\
\hline 5 & $46, \mathrm{XX}[11]$ & Female & 56 & Hypercellular & Low & RCDM \\
\hline 6 & NA & Female & 75 & NA & NA & RCDM \\
\hline 7 & NA & Male & 79 & NA & NA & RAEB-II \\
\hline 8 & $46, \mathrm{XY}[5]$ & Male & 71 & Hypercellular & Low & $\mathrm{RCDM}$ \\
\hline 9 & 46, XY[20] & Male & 80 & Hypercellular & Very low & $\mathrm{RCDM}$ \\
\hline 10 & NA & Female & 78 & Normocellular & NA & $\mathrm{RCDM}$ \\
\hline 11 & $46, X X \operatorname{del}(7)(q 32)[5]+\operatorname{mar}[3] / 46 x x[12]$ & Female & 81 & NA & Intermediate & $\mathrm{RCDM}$ \\
\hline 12 & $46, \mathrm{XX}[20]$ & Female & 91 & Hypercellular & Low & RCDM \\
\hline 13 & $46, \mathrm{XX}[27]$ & Female & 78 & Hypercellular & Low & RAEB-II \\
\hline 14 & NA & Male & 80 & Hypercellular & NA & RARS \\
\hline 15 & $\begin{array}{l}37, X,-2,-3,-9,-11,-12,-15,-16,-18,-Y[8] / 46, X Y, \operatorname{del}(5)(q 15 q 33)[5] / \\
\quad 46, X Y[6]\end{array}$ & Male & 71 & Hypercellular & High & RAEB-II \\
\hline 16 & 46,XX,del7(q32)[6]/46,XX[8] & Female & 75 & NA & Intermediate & RARS \\
\hline 17 & NA & Female & 87 & Hypercellular & NA & RCDM \\
\hline 18 & NA & Female & 90 & Hypercellular & NA & RCDM \\
\hline 19 & NA & Female & 70 & Hypercellular & NA & $\mathrm{RCDM}$ \\
\hline 20 & 46, XY[10] & Male & 72 & Hypercellular & Very low & $\mathrm{RCDM}$ \\
\hline 21 & $\begin{array}{l}\text { 46,XY,del(4)(q28q32)[4]/46,XY,del(7)(q32)[3]/ } \\
\text { 46,XY,del(4)(q28q32),del(7)(q32)[3]/46,XY[15] }\end{array}$ & Male & 70 & Normocellular & Low & RCDM \\
\hline 22 & NA & Female & 77 & NA & NA & RAEB-II \\
\hline 23 & 46, XY,add(12)q(24.33)(2), 46XY,del(17)/46 XY [5] & Male & 71 & Hypercellular & Intermediate & $\mathrm{RCDM}$ \\
\hline 24 & 46, XX [12] & Female & 80 & Hypercellular & Low & $\mathrm{RCDM}$ \\
\hline 25 & 46, XX, del (5)(q22)[8]/46, XX [8] & Female & 68 & Hypocellular & Very low & RCDM \\
\hline
\end{tabular}

$B M C$ bone marrow cellularity; IPSS-R International Prognosis Score System Revised; WHO World Health Organization; $R A R S$ refractory anemia with ringed sideroblasts; $R A E B$ refractory anemia with excess blasts type I or type II; $R C D M$ refractory cytopenia with multilineage dysplasia; $N A$ not available

by $50 \mu \mathrm{L}$ of a secondary antibody conjugated to horseradish peroxidase (HRP). After incubation for $1 \mathrm{~h}$, at room temperature without agitation, $50 \mu \mathrm{L}$ of chemiluminescent working solution was added to all wells. The specific binding was detected by chemiluminescence.

IL-8 protein concentrations were measured by a commercial ELISA kit (BD OptEIA San Diego, California, USA) according to protocol instructions. The plate was sensitized with capture antibody and was incubated overnight. The plate was blocked with the assay diluent. Samples and standards were added and further incubated. Working detector was added and incubated. Between each step washes were performed. Substrate solution was then added and incubated at room temperature in dark room.
Finally, stop solution was added and the reading was performed at $450 \mathrm{~nm}$ absorbance.

For statistical analysis, data on IL-8 and NF-kB quantification were expressed as median and range (minimum and maximum). The Mann-Whitney test was used to analyze the influence of IL- 8 and NF-kB in clinicopathological variables of MDS patients. The Spearman's correlation test was used for obtaining the $r$ and the $r$-square $\left(r^{2}\right)$ values. Statistical analyses were performed using the GraphPad Prism 5 (GraphPad Prism software, La Jolla, CA, USA) and SPSS 20.0 (SPSS Inc., Chicago, IL, USA) computer software programs. Probability level ( $p$ value) $<0.05$ was adopted as a significance criterion. 
A
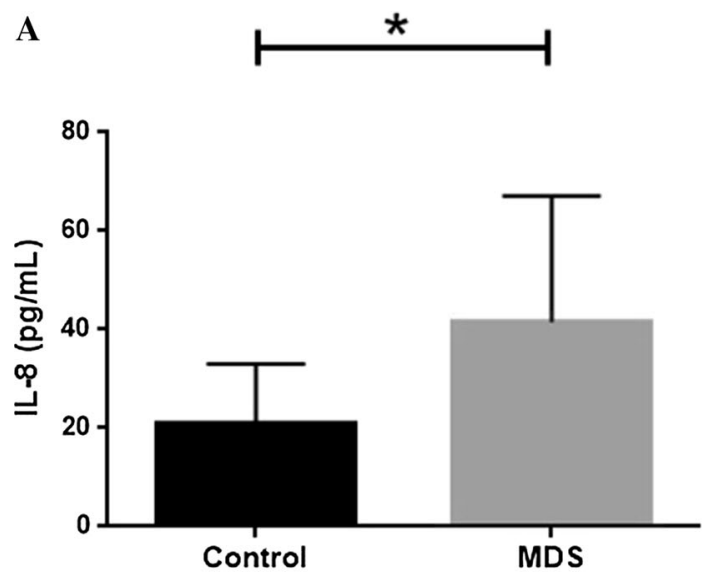

B
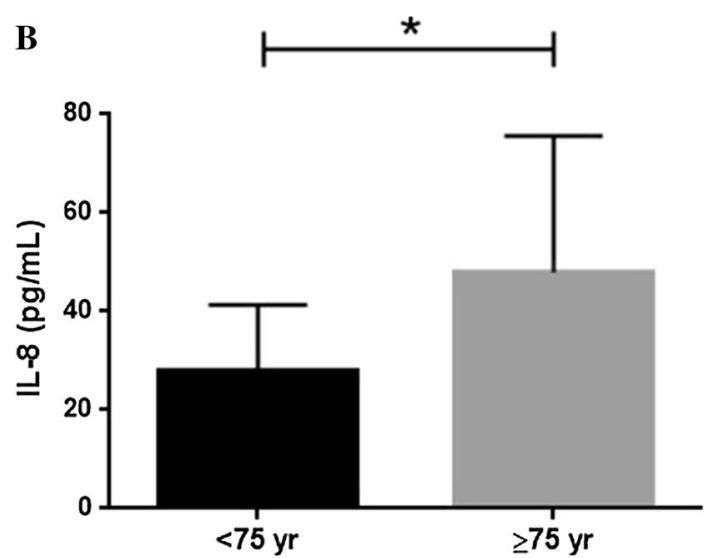

Asterisk in bold indicates significant differences $(\boldsymbol{p}<0.05)$ between groups.

Fig. 1 Plots of IL-8 analysis in MDS patients and controls (a) and in MDS patients according to age (b)

\section{Results}

A total of 45 individuals were included: 25 consecutive adult de novo MDS patients and 20 controls. Characteristics of MDS patients are shown in Table 1. According to WHO classification, there were 4 RARS, 16 RCDM and 5 RAEB, most of them (68\%) aged above 75 years. From patients with cytogenetic analysis, available karyotype was normal in $47 \%$ of patients and abnormal in 53\%. From abnormal results, $23.5 \%$ were stratified as very low risk, $41.2 \%$ as low risk, $23.5 \%$ as intermediate risk and $11.8 \%$ as high risk, according to IPSS-R (Table 1). Bone marrow was hypocellular in $5.8 \%$ patients, normocellular in $11.9 \%$ and hypercellular in $82.3 \%$.

MDS patients showed higher level of IL-8 when compared to controls $(p=0.006)$ (Fig. 1a). Patients aged 75 and above showed significant higher levels ( $p=0.035$ ) (Fig. 1b). No significant associations were found between level of IL-8 and the following variables: serum ferritin, iron overload, concentration of hemoglobin, neutrophils count, platelets count, endogenous erythropoietin, number of cytopenias, percent of blasts, cytogenetic abnormalities, WHO classification or IPSS-R score (Table 2).

NF-kB activity was significantly elevated in MDS patients when compared to controls $(p<0.001)$ (Fig. 2a) and higher in patients older than 75 years $(p=0.047)$ (Fig. 2b). NF-kB activity was associated with higher serum ferritin $(p=0.032)$ (Fig. 2c) and higher percentage of blasts $(p=0.042)$ (Fig. 2d). No significant associations were found between the NF-kB and the following variables: iron overload, concentration of hemoglobin, neutrophils count, platelets count, endogenous erythropoietin, number of cytopenias, cytogenetic abnormalities, WHO classification or IPSS-R score (Table 2).

The study of correlation between IL- 8 and NF-kB in MDS patients showed a significant positive moderate correlation between IL-8 and NF-kB ( $r=0.480 ; p=0.015)$. The $r$-squared $\left(r^{2}=0.232\right)$ showed that $23.2 \%$ of the variance is shared between IL-8 and NF-kB (Fig. 3).

\section{Discussion}

The age-related chronic upregulation of the inflammatory immune response with increased levels of proinflammatory cytokines, known as "inflammaging," is believed to be a consequence of chronic antigenic stimulation and has an important role in the development of age-associated diseases [22].

Disordered modulation of hematopoiesis during aging and the abnormal chronic cytokines signaling have negative effects on hematopoietic stem cell (HSC) regulation and function and are contributing factors to the emergence of abnormal clones. In MDS, abnormal levels of cytokines and chemokines have been recently documented $[5,12,23]$ and have been implicated in the pathogenesis of the disease: "the unexpected role of inflammatory signaling beyond inflammation" [24]. In this study, serum level of IL-8 and activation of NF-kB were significantly higher in MDS patients as compared to controls. Probably because abnormal regulation of cytokine production is an age-related event, patients older than 75 years presented even higher levels of both parameters.

Excess of iron enhance the generation of reactive oxygen species (ROS), with a cascade of consequences. ROS damage DNA, risking genomic instability, mutagenesis and cell death or neoplasia. Moreover, ROS directly activate caspases accelerating apoptotic death and, paradoxically, may also have anti-apoptotic effects by activating NF-kB which may contribute to MDS transformation [25]. Activation of NF-kB and activation of iron overload, defined as serum ferritin $\geq 1000 \mathrm{ng} / \mathrm{mL}$, are both considered markers 
Table 2 Analysis of IL-8 and NF-kB according to clinicopathological variables of MDS patients

\begin{tabular}{|c|c|c|c|c|c|c|}
\hline Variables & $N(\%)$ & $\begin{array}{l}\text { IL-8 (ng/dL) } \\
\text { Median (min-max) }\end{array}$ & $p^{*}$ & $N(\%)$ & $\begin{array}{l}\text { NF-kB (UF) } \\
\text { Median (min-max) }\end{array}$ & $p^{*}$ \\
\hline \multicolumn{7}{|l|}{ Group } \\
\hline Control & $15(100.0)$ & $18.58(1.71-38.73)$ & \multirow[t]{2}{*}{0.006} & $19(100.0)$ & $1.064(947.0-1.144)$ & \multirow[t]{2}{*}{$<0.0001$} \\
\hline MDS & $25(100.0)$ & $35.53(16.9-118.8)$ & & $25(100.0)$ & $1.172(1.049-1.335)$ & \\
\hline \multicolumn{7}{|l|}{ Age } \\
\hline$<75$ years & $8(32.0)$ & $23.13(16.90-19.02)$ & \multirow[t]{2}{*}{0.035} & $8(32.0)$ & $1.108(1.049-1.167)$ & \multirow[t]{2}{*}{0.0476} \\
\hline$\geq 75$ years & $17(68.0)$ & $39.92(17.61-118.8)$ & & $17(68.0)$ & $1.174(1.109-1.335)$ & \\
\hline \multicolumn{7}{|l|}{ WHO } \\
\hline RARS & $4(16.0)$ & 59.14 (39.92-91.93) & \multirow[t]{3}{*}{0.078} & $4(16.0 .0)$ & $1.169(1.132-1.256)$ & \multirow[t]{3}{*}{0.345} \\
\hline RCDM & $16(64.0)$ & $28.63(16.90-77.24)$ & & $16(64.0)$ & $1.167(1.049-1.335)$ & \\
\hline RAEB & $5(20.0)$ & $40.58(17.61-118.8)$ & & $5(20.0)$ & $1.192(1.063-1.280)$ & \\
\hline \multicolumn{7}{|l|}{ Ferritin $(n g / m L)$} \\
\hline$<500$ & $11(44.0)$ & $36.64(18.23-118.8)$ & \multirow[t]{2}{*}{0.341} & 11(44.0) & $1.144(1.049-1.280)$ & \multirow[t]{2}{*}{0.032} \\
\hline$\geq 500$ & $14(56.0)$ & $28.82(16.90-91.93)$ & & $14(56.0)$ & $1.180(1063-1.335)$ & \\
\hline \multicolumn{7}{|l|}{ Iron overload } \\
\hline Yes & $10(40.0)$ & $23.46(16.90-91.93)$ & \multirow[t]{2}{*}{0.061} & $10(40.0)$ & $1.180(1.063-1.335)$ & \multirow[t]{2}{*}{0.266} \\
\hline No & $15(60.0)$ & $36.64(18.23-118.8)$ & & $15(60.0)$ & $1.162(1.049-1.280)$ & \\
\hline \multicolumn{7}{|l|}{ Hemoglobin $(\mathrm{g} / \mathrm{dL})$} \\
\hline$\leq 8$ & $8(32.0)$ & $38.06(16.90-91.93)$ & \multirow{3}{*}{0.447} & $8(32.0)$ & $1.188(1.144-1.335)$ & \multirow{3}{*}{0.121} \\
\hline$>8$ to $\leq 10$ & $10(40.0)$ & $27.18(17.61-77.24)$ & & $10(40.0)$ & $1.155(1.049-1.197)$ & \\
\hline$>10$ & $7(28.0)$ & $35.64(25.04-118.8)$ & & $7(28.0)$ & $1.172(1.063-1.280)$ & \\
\hline \multicolumn{7}{|l|}{ Neutrophils $\left(\mathrm{mm}^{3}\right)$} \\
\hline$<800$ & $9(36.0)$ & 35.64 (16.90-91.93) & \multirow[t]{2}{*}{0.697} & $9(36.0)$ & $1.187(1.063-1.335)$ & \multirow[t]{2}{*}{0.379} \\
\hline$\geq 800$ & $16(64.0)$ & $32.26(18.23-118.8)$ & & $16(64.0)$ & $1.172(1.049-1.280)$ & \\
\hline \multicolumn{7}{|l|}{ Platelets $\left(\mathrm{mm}^{3}\right)$} \\
\hline$\leq 50.000$ & $2(8.0)$ & $26.27(16.90-35.64)$ & \multirow{3}{*}{0.116} & $2(8.0)$ & $1.112(1.063-1.160)$ & \multirow{3}{*}{0.386} \\
\hline$>50,000$ to $\leq 100,000$ & $10(40.0)$ & $27.16(17.65-91.93)$ & & $10(40.0)$ & $1.172(1.109-1.335)$ & \\
\hline$>100,000$ & $13(52.0)$ & $54.56(17.61-118.8)$ & & $13(52.0)$ & $1.176(1.049-1.280)$ & \\
\hline Number of cytopenias & & & & & & \\
\hline 1 & $8(32.0)$ & $48.04(18.23-62.11)$ & & $8(32.0)$ & $1.160(1.049-1.197)$ & \\
\hline 2 & $7(28.0)$ & $25.71(20.36-40.58)$ & 0.388 & $7(28.0)$ & $1.171(1.105-1.192)$ & 0.408 \\
\hline 3 & $10(40.0)$ & $36.14(16.9-118.8)$ & & $10(40.0)$ & $1.186(1.335-1.063)$ & \\
\hline Erythropoietin (mUI/mL) & & & & & & \\
\hline$\leq 500$ & $8(72.0)$ & 48.04 (17.65-91.93) & 0.545 & $8(72.0)$ & $1.176(1.132-1.335)$ & 0.660 \\
\hline$>500$ & $3(28.0)$ & $35.53(17.61-77.24)$ & & $3(28.0)$ & $1.176(1.063-1.178)$ & \\
\hline Percent of blasts (\%) & & & & & & \\
\hline$\leq 5$ & $19(82.0)$ & 28.99 (16.9-91.93) & 0.365 & $19(82.0)$ & $1.162(1.049-1.335)$ & 0.042 \\
\hline$>5$ & $4(18.0)$ & $47.57(21.22-118.8)$ & & $4(18.0)$ & $1.194(1.184-1.280)$ & \\
\hline Karyotype & & & & & & \\
\hline Normal & $8(47.0)$ & $28.8(17.61-118.8)$ & 0.727 & $8(47.0)$ & $1.129(1.049-1.280)$ & 0.208 \\
\hline Abnormal & $9(53.0)$ & $25.71(16.90-91.93)$ & & $9(53.0)$ & $1.175(1.105-1.355)$ & \\
\hline$I P S S-R$ & & & & & & \\
\hline Very low + Low & $11(64.7)$ & $28.61(17.61-91.93)$ & 0.617 & $11(64.7)$ & $1.109(1.049-1.256)$ & 0.073 \\
\hline Intermediate + High + Very high & $6(35.3)$ & $24.93(16.90-118.8)$ & & $6(35.3)$ & $1.186(1.144-1.335)$ & \\
\hline
\end{tabular}

Numbers in bold indicate significant difference $(p<0.05)$ between groups analyzed by Mann-Whitney 
Fig. 2 Plots of NF-kB analysis in MDS patients and controls (a), in MDS patients according to age (b), to serum ferritin (ng/ $\mathrm{mL})(\mathbf{c})$ and to percentage of blasts (d)
$\mathbf{A}$
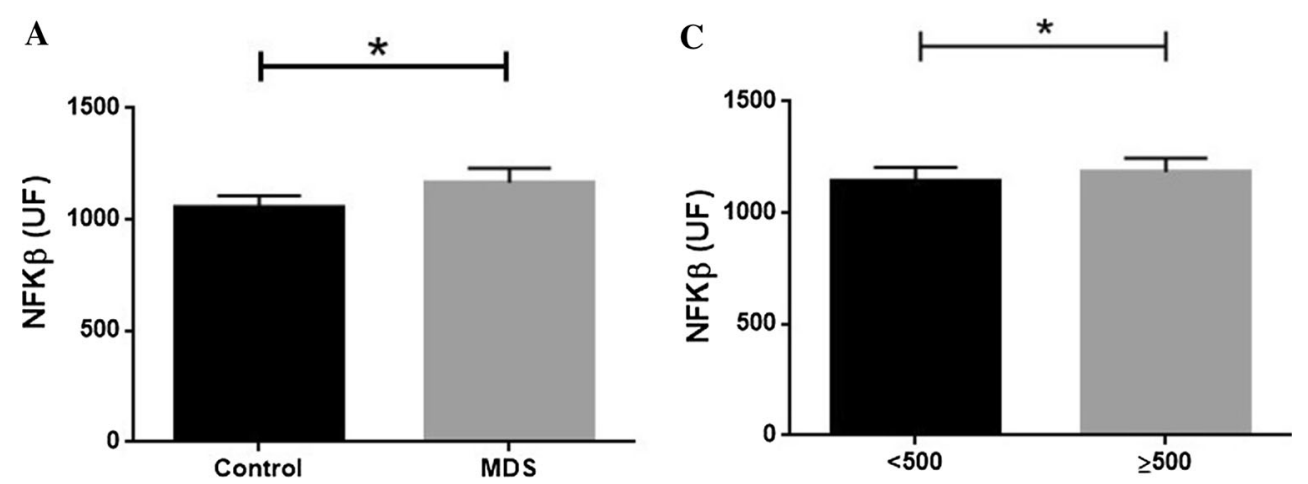

B
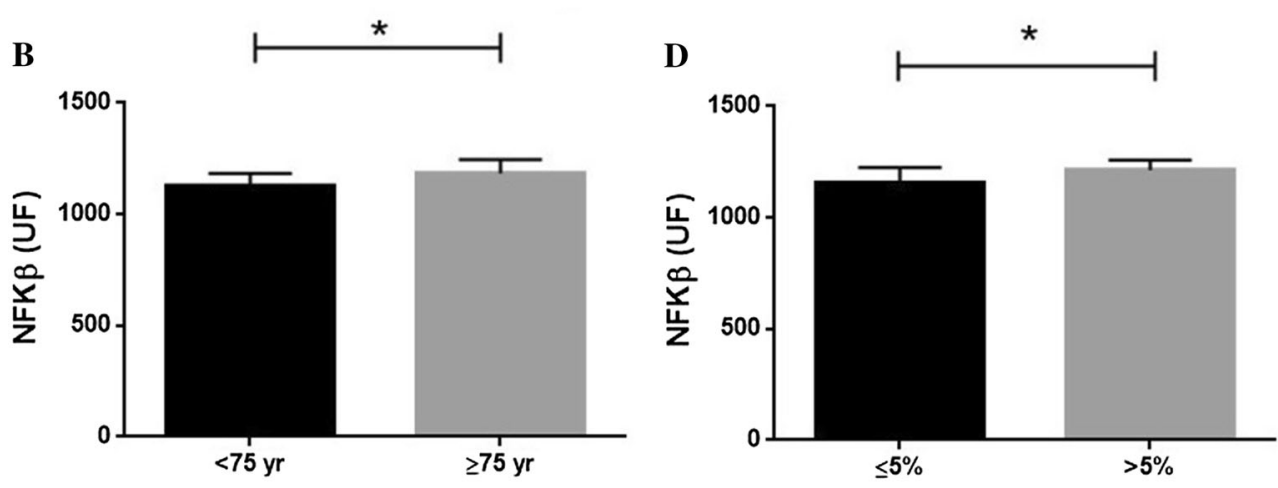

Asterisk in bold indicates significant differences $(p<0.05)$ between groups.

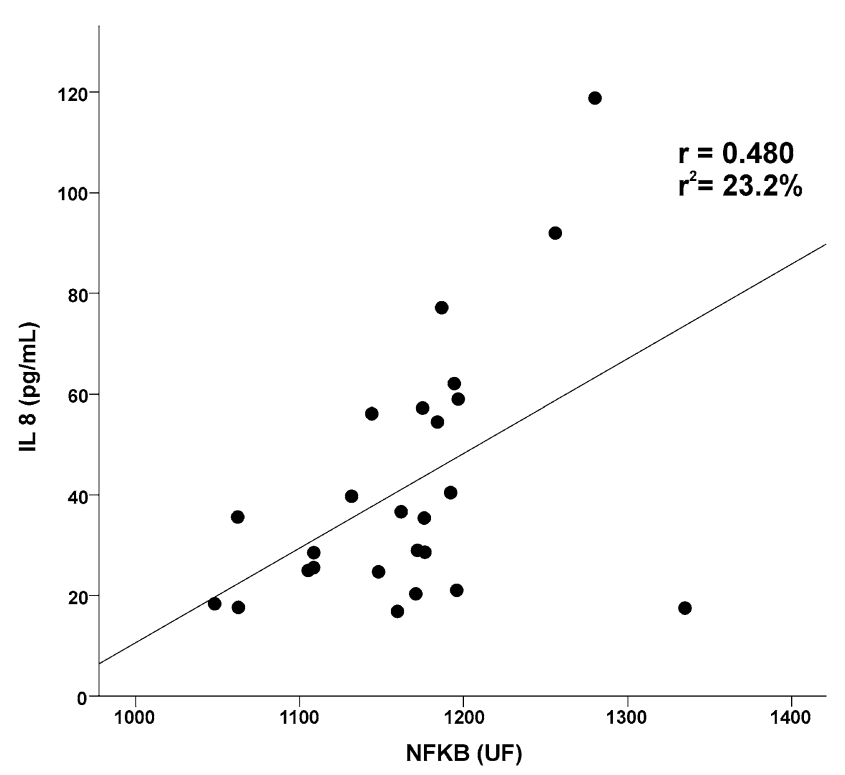

Fig. 3 Plot of Spearman's correlation analysis between IL-8 and NF$\mathrm{kB}$ in MDS patients

of poor prognosis. Of interest, in this study, a significant association was detected between elevated activation of NF-kB and even slightly elevated ferritin ( $\geq 500 \mathrm{ng} / \mathrm{mL}$ ). The oral chelator deferasirox is a potential inhibitor of NF$\mathrm{kB}$, an effect that seems to be independent of the decrease in ferritin levels [26].
Some previous studies suggested that inflammatory intermediates can induce DNA instability and promote the emergence of mutant clones, supporting a model for MDS pathogenesis in which sustained immune system deregulation in the bone marrow microenvironment creates a permissive milieu for the development of MDS [27]. Therefore, the inflammatory process in MDS has been postulated to represent a primary pathophysiologic abnormality and a key driver of the evolution of disease. Although IL-8 has been proposed as a universal biomarker and has currently been applied as predictor of prognosis in various diseases, including solid tumors and non-Hodgkin's lymphoma [9], in this series, isolated high level of IL8 was significantly associated with MDS but not with higher-risk MDS. A higher number of cases are necessary to confirm these data.

Pro-apoptotic signaling is strongly associated with lower-risk MDS. Higher-risk MDS is associated with decreased apoptotic index, either by downregulation of pro-apoptotic cytokines or as a result of anti-apoptotic effects. Elevated activation of NF-kB is an important prosurvival factor of MDS progenitors. An association between elevated NF-kB activity with higher-risk subgroups of the disease was observed in this study, when evaluated either by excess of blast or by IPSS-R subgroups.

The NF-kB is potentially activated in response to a variety of stimuli such as carcinogens, bacterial and viral 
proteins, endotoxins and inflammatory agents [15]. Therefore, it was of interest to test correlation between NF$\mathrm{kB}$ and the inflammatory cytokine IL-8. In this study, a significant, positive and moderate correlation was demonstrated between these two factors. Of utmost importance, we detected that IL- 8 was responsible for $23.2 \%$ of the increase in NF-kB, reinforcing its cooperation. IL-8 and NF-kB have both a diversity of effectors and downstream targets promoting angiogenic response, increase in proliferation, migration and survival of cancer cells. They are probably part of a complex networking of immune and inflammatory factors involved in pathogenesis of MDS. This is an instigating subject of research and this study provides a rationale for further deeper evaluation of the role and cooperation of IL-8 and NF-kB as part of a complex networking of immune and inflammatory factors involved in MDS.

Acknowledgements This study was conducted with partial support from National Counsel of Technological and Scientific Development (CNPq) and Cearense Foundation for the Support of Scientific and Technological Development (FUNCAP).

Author contributions AGM, HLRJ, DPB, BMO, JCS, MCB, MFC, RPG, RFP and SMMM designed the study, provided patient materials and were responsible for collection and assembly of data. All drafted and edited the manuscript. All authors have approved the final version of manuscript before publication.

\section{Compliance with ethical standards}

Conflict of interest The authors declare that there is no conflict of interest.

Ethical approval This study was approved by Committee of Ethics in Research with Human Beings of Walter Cantídio University Hospital/Federal University of Ceara (\#1.359.984).

\section{References}

1. Gangat N, Patnaik MM, Tefferi A. Myelodysplastic syndromes: contemporary review. Am J Hematol. 2016;91:76-89.

2. Magalhaes SMM, Madeira TS, Bittencourt R, Velloso E, de Lourdes Chauffaille M, Azevedo AA, et al. Epidemiological and clinicopathological data from the Brazilian registry of patients with myelodysplastic syndromes and comparative analysis between different geographic areas. Blood. 2010;116(21):1884.

3. Magalhães SMM, Heredia FF, Fernandes LC, Sousa J, Almeida PJ, Souza GF, et al. Beyond race-related disparities: is myelodysplastic syndrome the same everywhere? Leuk Lymphoma. 2013;54:1564-6.

4. Belli CB, Pinheiro RF, Bestach Y, et al. Myelodysplastic syndromes in South America: a multinational study of 1080 patients. Am J Hematol. 2015;90:851-8.

5. Gañán-Gómez I, Wei Y, Starczynowski DT, et al. Deregulation of innate immune and inflammatory signaling in myelodysplastic syndromes. Leukemia. 2015;29:1458-69.
6. Zahid MF, Patnaik MM, Gangat $\mathrm{N}$, et al. Insight into the molecular pathophysiology of myelodysplastic syndromes. Eur J Haematol. 2016;97:313-20. doi:10.1111/ejh.12771.

7. GlenthØj A, Ørskov AD, Hansen JW, Sine RH, O'Connell C, Grønbæk K. Immune mechanisms in myelodysplastic syndrome. Int J Mol Sci. 2016;17:944.

8. Wolach O, Stone R. Autoimmunity and inflammation in myelodysplastic syndromes. Acta Haematol. 2016;136:108-17.

9. Shahzad A, Knapp M, Lang I. Interleukin-8: a universal biomarker? Int Arch Med. 2010;3:11.

10. Waugh DJJ, Wilson C. The interleukin-8 pathway in cancer. Clin Cancer Res. 2008;14:6735-41.

11. Schinke C, Giricz O, Li WL, et al. IL8-CXCR2 pathway inhibition as a therapeutic strategy against MDS and AML stem cells. Blood. 2015;125:3144-52.

12. Kornblau SM, McCue D, Singh N, et al. Recurrent expression signatures of cytokines and chemokines are present and are independently prognostic in acute myelogenous leukemia and myelodysplasia. Blood. 2010;116:4251-61.

13. Singh J, Simões BM, Howell SJ, et al. Recent advances reveal IL8 signaling as a potential key to targeting breast cancer stem cells. Breast Cancer Res. 2013;15:210.

14. Zhang M, Fanf T, Wang K, et al. Association of polymorphisms in interleukin-8 gene with cancer risk: a meta-analysis of 22 case-control studies. Onco Targets Therapy. 2016;9:3727-37.

15. Aggarwal BB. Nuclear factor-kB: the enemy within. Cancer Cell. 2004;6:203-8.

16. Braun T, Carvalho G, Coquelle A, et al. NFkB constitutes a potential therapeutic target in high-risk myelodysplastic syndrome. Blood. 2006;107:1156-65.

17. Ben-Neriah Y, Karin M. Inflammation meets cancer, with NF-kB as the matchmaker. Nat Immunol. 2011;12(8):715-23.

18. Gilmore TD. Introduction to NF-kB: players, pathways, perspectives. Oncogene. 2006;25:6680-4.

19. Greenberg PL, Tuechler H, Schanz J, et al. Revised international prognostic scoring system for myelodysplastic syndromes. Blood. 2012;120(12):2454-65.

20. Vardiman JW, Thiele J, Arber DA, et al. The 2008 revision of the World Health Organization (WHO) classification of myeloid neoplasms and acute leukemia: rationale and important changes. Blood. 2009;114:937-51.

21. Bradford MM. A rapid and sensitive method for the quantitation of microgram quantities of protein utilizing the principle of protein-dye binding. Anal Biochem. 1976;72:248-54.

22. Flülöp T, Dupuis G, Witkowski JM, et al. The role of immunosenescence in the development of age-related diseases. Rev Invest Clin. 2016;68:84-91.

23. Meyers CA, Albitar M, Estey E. Cognitive impairment fatigue and cytokine levels in patients with acute myelogenous leukemia or myelodysplastic syndrome. Cancer. 2005;104:788-93.

24. He Q, Liu F. Unexpected role of inflammatory signaling in hematopoietic stem cell development: its role beyond inflammation. Curr Opin Hematol. 2016;23:18-22.

25. Porter JB, Garbowski M. The pathophysiology of transfusional iron overload. Hematol Oncol Clin N Am. 2014;28:683-701.

26. Banerjee A, Mifsud NA, Bird R, et al. The oral iron chelator deferasirox inhibits NF-kB mediated gene expression without impacting on proximal activation: implications for myelodysplasia and aplastic anemia. Br J Haematol. 2015;168:576-82.

27. Yang L, Qian Y, Eksioglu E, et al. The inflammatory microenvironment in MDS. Cell Mol Life Sci. 2015;72:1959-66. 